\title{
The effect of cytokinins on shoot proliferation, secondary metabolite production and antioxidant potential in shoot cultures of Scutellaria alpina
}

\author{
Izabela Grzegorczyk-Karolak $^{1} \cdot$ Lukasz Kuźma $^{1} \cdot$ Halina Wysokińska $^{1}$
}

Received: 3 December 2014/ Accepted: 5 June 2015/Published online: 14 June 2015

(c) The Author(s) 2015. This article is published with open access at Springerlink.com

\begin{abstract}
The present study evaluates the effects of various cytokinins on Scutellaria alpina shoot proliferation and production of polyphenolic metabolites (baicalin, wogonoside, luteolin, luteolin 7-O-glucoside, verbascoside). The shoots were induced from shoot tips on MS medium supplemented with IAA (indole-3-acetic acid, $0.57 \mu \mathrm{M})$ and various concentrations of 6-benzylaminopurine (BAP), kinetin, zeatin $(1,2,4,8 \mu \mathrm{M})$ or tidiazuron (TDZ) $(0.2,0.5,1 \mu \mathrm{M})$. Among the cytokinins tested, BAP was the most effective for shoot induction, and the highest number of shoots (25 per explant) was achieved with 2 and $4 \mu \mathrm{M}$ BAP. Maximum biomass production was also achieved on these media. Significantly higher baicalin, wogonoside and verbascoside contents were recorded in treatments containing cytokinins combined with $0.57 \mu \mathrm{M}$ IAA, when compared to cytokinin-free medium. TDZ at a concentration of $0.5 \mu \mathrm{M}$ was the most effective for polyphenol production. However, supplementation with cytokinins often results in the reduction of luteolin and its 7-O-glucoside production in the shoot culture of $S$. alpina. ABTS [2,2'-azino-bis(3-ethylbenzothiazoline-6-sulphonic acid)] and ferric reducing antioxidant power assays were used to identify the antioxidant potential of methanolic extracts from shoots cultured in the presence of different types and concentrations of cytokinins. In both tests, the shoots from medium supplemented with $0.5 \mu \mathrm{M}$ TDZ demonstrated the strongest antioxidant activity. The results
\end{abstract}

Izabela Grzegorczyk-Karolak

izabela.grzegorczyk@umed.lodz.pl

1 Department of Biology and Pharmaceutical Botany, Medical University of Łódź, ul. Muszyńskiego 1, 90-151 Lodz, Poland indicate that higher polyphenolic content correlated with greater reducing power and antiradical efficiency.

Keywords Antioxidant activity - Axillary shoots . Cytokinins - Flavonoid and verbascoside contents . Scutellaria alpina

\section{Introduction}

The genus Scutellaria (Lamiaceae) comprises about 300 species, which are distributed in Europe, the United States and East Asia. Many of the plants belonging to the Scutellaria genus have been used for centuries in traditional Chinese medicine for the treatment of hyperlipidemia, arteriosclerosis, allergy, antibacterial and inflammatory diseases (Shang et al. 2010). The pharmacological properties of the plants are mainly due to the presence of flavonoids such as baicalein, baicalin, wogonin and wogonoside (Shang et al. 2010). Baicalein is known to have a neuroprotective effect against MPTP (1-methyl-4-phenyl-1, 2, 3, 6-tetrahydropyridine) neurotoxicity (Cheng et al. 2008). The flavone protects rat brain mitochondria against chronic cerebral hyperfusion-induced oxidative damage (He et al. 2009). Its glucoside, baicalin, is a potent anti-inflammatory and antitumor agent (Chang et al. 2002; Woo et al. 2006; Shang et al. 2010). Animal experimentation has shown that baicalin can ameliorate the intestinal cytotoxicity caused by the antitumor agent Cpt-11 (Takasuna et al. 1995). It inhibits HIV-1 infection and replication by inhibiting HIV-1 reverse transcriptase (Kitamura et al. 1998). Wogonoside inhibits lipopolysaccharide-induced angiogenesis (Chen et al. 2009). It demonstrates strong activity against lipid peroxidation and an inhibitory effect on histamine and IgE production (Lim 2003). 
Besides flavonoids, the phenylethanoid glycosides, verbascoside and martynoside have been isolated from some species of Scutellaria (Shang et al. 2010). Verbascoside has been found to have a wide spectrum of biological properties, demonstrating antibacterial (Shoyama et al. 1986), antiviral (Kernan et al. 1998), antioxidant (Gao et al. 1999) and cytotoxic activities (Pettit et al. 1990).

Due to the pharmacological importance of the secondary metabolites of Scutellaria, interest has grown in the use of biotechnological methods to increase production. Plant tissue culture offers a valuable alternative method for plant micropropagation and the production of biologically active substances under controlled conditions, regardless of season. In recent years, various strategies have been developed which could increase the accumulation of biomass and biosynthesis of secondary metabolites in plant cell and organ cultures (Cole et al. 2007). Attempts to produce phytochemicals of Scutellaria species through tissue culture have been reported earlier for $S$. baicalensis, $S$. columnae, S. lateriflora and S. racemosa (Seo et al. 1993; Nishikawa and Ishimura 1997; Stojakowska and Kisiel 1998; Cole et al. 2008). Previous studies describe the successful establishment of shoot regenerating calli and whole plants of S. altissima and these have been found to produce important secondary metabolites (GrzegorczykKarolak et al. 2013, 2015). Following on from these studies, the present study focuses on shoot cultures of $S$. alpina, a perennial herb distributed throughout the mountain regions of central and southern Europe. The species is characterized by the presence of both valuable flavonoids and high levels of verbascoside (Nishikawa et al. 1999), making it particularly suitable for the present study. This paper reports the effect of different cytokinines (BAP, zeatin, kinetin, TDZ) on the growth of shoot cultures of $S$. alpina, their capacity to produce flavonoids (baicalin, wogonoside, luteolin, luteolin 7-glucoside) and verbascoside, and their antioxidant activity.

\section{Materials and methods}

\section{Establishment of in vitro culture}

Scutellaria alpina seeds provided by the Botanical Garden of the Institute of Ecology and Botany in Vacratot (Hungary) were used to initiate in vitro culture. The seeds were washed in running tap water, surface sterilized using sodium hypochlorite $(1 \%)$ for $10 \mathrm{~min}$ and then rinsed three times in sterile distilled water. They were placed on MS (Murashige and Skoog 1962) agar (0.7 \%) medium supplemented with kinetin $0.02 \mathrm{mg} \mathrm{l}^{-1}$ and gibberellic acid $1 \mathrm{mg} \mathrm{l}^{-1}$ for germination. The shoot culture was initiated from shoot tips of 3-week-old aseptically germinated seedlings. The explants were grown on MS agar medium supplemented with $0.57 \mu \mathrm{M} 3$-inoliloacetic acid (IAA) and $2 \mu \mathrm{M}$ 6-benzylaminopurine (BAP), and were subcultured every 5 weeks (Grzegorczyk-Karolak et al. 2013). All cultures were kept at $26 \pm 2{ }^{\circ} \mathrm{C}$ under a $16 \mathrm{~h}$ photoperiod provided by cool white fluorescent lamps (approximately $40 \mu \mathrm{mol} \mathrm{m}^{-2} \mathrm{~s}^{-1}$ ).

\section{Shoot proliferation and biomass production}

The shoot tips $(0.5 \mathrm{~cm})$ of in vitro growing shoots of $S$. alpina were used as starting material in the experiments. The explants were incubated in tubes containing $25 \mathrm{ml}$ of MS agar medium supplemented with $0.57 \mu \mathrm{M}$ IAA and various types and concentrations of cytokinin $(1,2,4$, $8 \mu \mathrm{M}$ BAP, zeatin or kinetin and $0.2,0.5$ or $1 \mu \mathrm{M}$ TDZ). Shoot tips grown on MS medium without cytokinin, only with $0.57 \mu \mathrm{M}$ IAA, were used as a control. After 5 weeks, shoot fresh and dry weights [g/tube], the average number of shoots formed per explant (shoot multiplication rate), the length of the main shoots $[\mathrm{cm}]$ and shoot morphology in terms of hyperhydricity were recorded. Experiments were repeated three times, and each series consisted of 10-20 explants.

\section{Preparation of extracts}

This extraction was performed as described previously (Grzegorczyk-Karolak et al. 2015). Briefly, lyophilized plant material $(250 \mathrm{mg}$ for phytochemical analysis and $500 \mathrm{mg}$ for antioxidant assay) was pulverized and pre-extracted with chloroform overnight to remove chlorophyll. After filtration, the remaining plant material was extracted three times with $30 \mathrm{ml} 70 \%$ methanol for 15 min using an ultrasonic bath. The extracts were combined and evaporated under reduced pressure.

\section{Determination of secondary metabolites}

Ultra-high performance liquid chromatography (UPLC) was used for quantitative evaluation of the verbascoside, baicalin, wogonoside, luteolin and luteolin-7-O-glucoside content of shoots propagated on media with different types and concentrations of cytokinins. Chromatographic analysis was performed as described earlier for Scutellaria altissima (Grzegorczyk-Karolak et al. 2013) using an Agilent Technologies 1290 Infinity UPLC apparatus equipped with a diode array detector on a Zorbax Eclipse Plus C18 column $(100 \times 3 \mathrm{~mm} ; 1.8 \mu \mathrm{m}$ Agilent Technologies). The mobile phase consisted of $0.1 \%$ formic acid in acetonitrile (v/v) (solvent $\mathrm{A}$ ) and $0.1 \%$ formic acid in water (v/v) (solvent B). A gradient program was applied as follows: 0-15 $\min 20-30 \%$ solvent A, 15.1-17 $\min 99 \%$ 
solvent $\mathrm{A}$ at flow $0.3 \mathrm{ml} \mathrm{min}{ }^{-1}$. The detection wavelength was set at $320 \mathrm{~nm}$. In the analyzed samples, baicalin, wogonoside, luteolin, 7-O-glucoside of luteolin and verbascoside were identified by comparing their retention times (8.6, 13.6, 12.4, 4.1, 3.6 min., respectively), UV adsorption profiles and MS data with corresponding standard compounds. Liquid chromatography-mass spectrometry (LC-MS/MS) data of the compounds has been previously published (Grzegorczyk-Karolak et al. 2013, 2015).

Calibration curves were used to quantify the compounds. Linear standard curves were obtained by plotting standard concentration (baicalin: 220-1100 $\mu \mathrm{g} \mathrm{ml}^{-1}$, wogonoside: $320-1600 \mu \mathrm{g} \mathrm{ml}^{-1}$, luteolin: $220-1000 \mu \mathrm{g} \mathrm{ml}^{-1}$, luteolin-7-glucoside: $200-1000 \mu \mathrm{g} \mathrm{ml}^{-1}$ and verbascoside: 200-1000 $\mu \mathrm{g} \mathrm{ml}^{-1}$ ) as a function of peak area. The mean recovery values for the two fortification levels of the individual components were as follows: baicalin-112.8 and $100.63 \%$, wogonoside-95.11 and $99.44 \%$, luteolin-105.4 and $89.45 \%$, its glucoside-100.42 and $94.29 \%$, verbascoside- 95.48 and $93.07 \%$. The contents of the compounds in the tested plant materials were expressed as $\mathrm{mg} \mathrm{g}^{-1}$ of dry weight (wt).

\section{Antioxidant assays}

The antioxidant potential of methanolic extracts from $S$. alpina shoot cultures was evaluated using ABTS $\left[2,2^{\prime}-\right.$ azino-bis(3-ethylbenzothiazoline-6-sulphonic acid)] cation radical and ferric reducing antioxidant power (FRAP) assays.

\section{FRAP assay}

The FRAP assay was performed according to Pulido et al. (2000). Briefly, $3 \mathrm{ml}$ of freshly prepared FRAP reagent was mixed with $300 \mu \mathrm{l}$ redistilled water and $100 \mu \mathrm{l}$ of the methanol extract. The FRAP reagent was prepared by adding $2.5 \mathrm{ml} 10 \mathrm{mM}$ TPTZ (2,4,6-tris(2-pyridyl)-s-triazine) solution in $40 \mathrm{mM} \mathrm{HCl}, 2.5 \mathrm{ml}$ of $20 \mathrm{mM}$ aqueous $\mathrm{FeCl}_{3} \times 6 \mathrm{H}_{2} \mathrm{O}$ solution and $45 \mathrm{ml}$ of $0.3 \mathrm{M}$ acetate buffer at $\mathrm{pH}$ 3.6. The reaction mixture was incubated at $37^{\circ} \mathrm{C}$ for $15 \mathrm{~min}$. The absorbance was measured after $15 \mathrm{~min}$ at $595 \mathrm{~nm}$ relative to a blank (a sample containing methanol instead extract). The antioxidant activity was determined against a standard of known FRAP value: ferrous sulphate calculated from a calibration curve of $0-2000 \mu \mathrm{M}$.

\section{ABTS radical scavenging assay}

The antioxidant activity was also determined using the ABTS radical cation decolourisation test according to $\mathrm{Re}$ et al. (1999). An ABTS stock solution was prepared by mixing $7 \mathrm{mM}$ ABTS (Sigma Aldrich) with $2.45 \mathrm{mM}$ potassium persulfate (Sigma Aldrich). This mixture was kept in the dark at room temperature for $12-16 \mathrm{~h}$ before use. ABTS solution was diluted with methanol until an absorbance of $0.7 \pm 0.05$ was obtained at $734 \mathrm{~nm}$ for the negative control, which was prepared by mixing $2 \mathrm{ml}$ ABTS solution with $2 \mathrm{ml}$ of methanol. The assays were performed by adding $2 \mathrm{ml}$ of extracts (at concentrations of 2.0, 20.0, 100.0, 200.0, 500.0 and $1000.0 \mu \mathrm{g} \mathrm{ml}^{-1}$ ) to $2 \mathrm{ml}$ of ABTS solution. The absorbance was measured after $10 \mathrm{~min}$ at $734 \mathrm{~nm}$. The results were expressed as $\mathrm{EC}_{50}$ : the concentration of sample at which $50 \%$ of maximum scavenging activity was recorded.

\section{Statistical analysis}

The results were expressed as the means \pm (standard error) SE of three repeated independent experiments. The significance of the differences between the mean culture growth values was calculated using the Kruskal-Wallis test $(p \leq 0.05)$ test with Statistica 10.0 software (Statsoft Poland). Correlation analysis was also performed in order to determine relationships among variables.

\section{Results}

\section{Effect of cytokinins on shoot multiplication and biomass production}

The shoot tips of S. alpina were cultured on MS agar solidified medium supplemented with IAA $(0.57 \mu \mathrm{M})$ and a cytokinin: either BAP, kinetin, zeatin or TDZ. BAP, kinetin and zeatin were added to the medium at the concentrations of 1, 2, 4 or $8 \mu \mathrm{M}$. However, as the biological activity of TDZ is known to be generally higher than that of adenin-type cytokinins (Guo et al. 2011), it was used at lower concentrations in the present study $(0.2,0.5$ and $1 \mu \mathrm{M})$. Since the shoot tip explants did not grow on the hormone-free medium, shoots grown on MS medium supplemented with auxin $(0.57 \mu \mathrm{M}$ IAA) were used as control samples. The effect of cytokinins on axillary shoot proliferation of S. alpina and biomass, in terms of fresh and dry weight, were recorded after 5 weeks of culture. The results are presented in Figs. 1 and 2.

For all types and concentrations of cytokinins, the mean number of axillary shoots per S. alpina explant was higher, in most cases significantly, than those of the control MS medium supplemented only with $0.57 \mu \mathrm{M}$ IAA (Fig. 1). The most effective cytokinin was BAP, with the highest mean number of axillary shoots (25.0 per explant) being induced by BAP at $2 \mu \mathrm{M}$, and the number of shoots not being significantly different (at $p \leq 0.05$ ) compared with BAP at 
Fig. 1 The effect of various cytokinins and their concentrations on shoot proliferation of S. alpina and their length after 5 weeks of culture on MS medium with IAA $(0.57 \mu \mathrm{M})$. The results are expressed as means of three replicates $\pm \mathrm{SE}$. The means with the same letter for the same parameter do not differ significantly according to the Kruskal-Wallis test $(p \leq 0.05)$
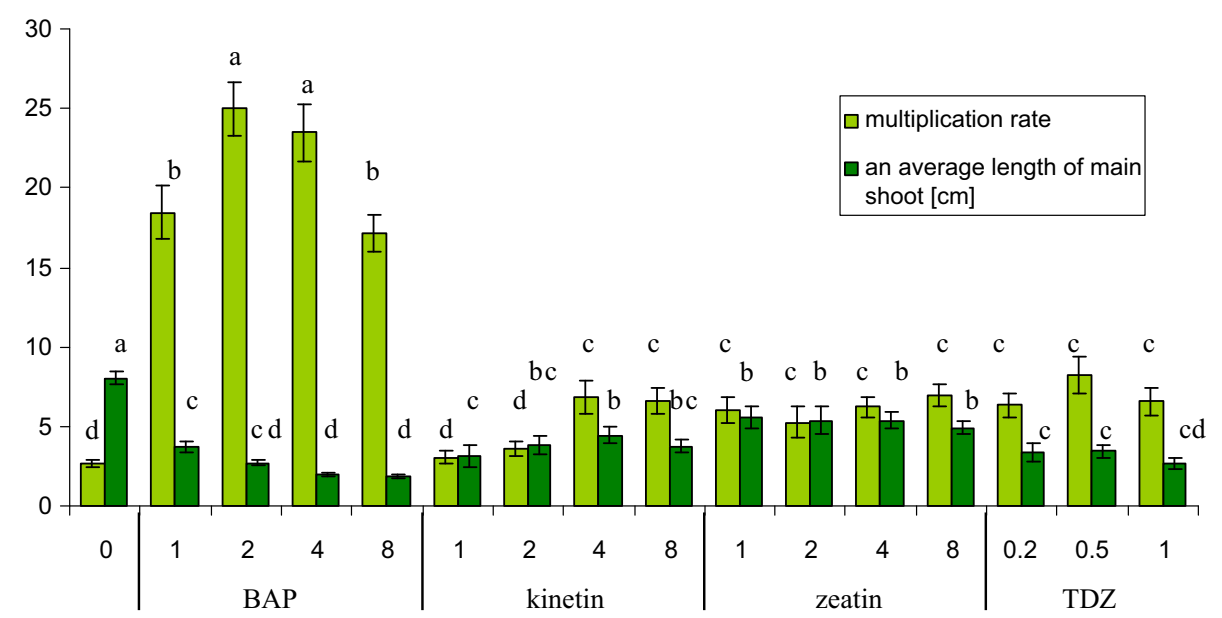

cytokinin type and concentration $[\mu \mathrm{M}]$

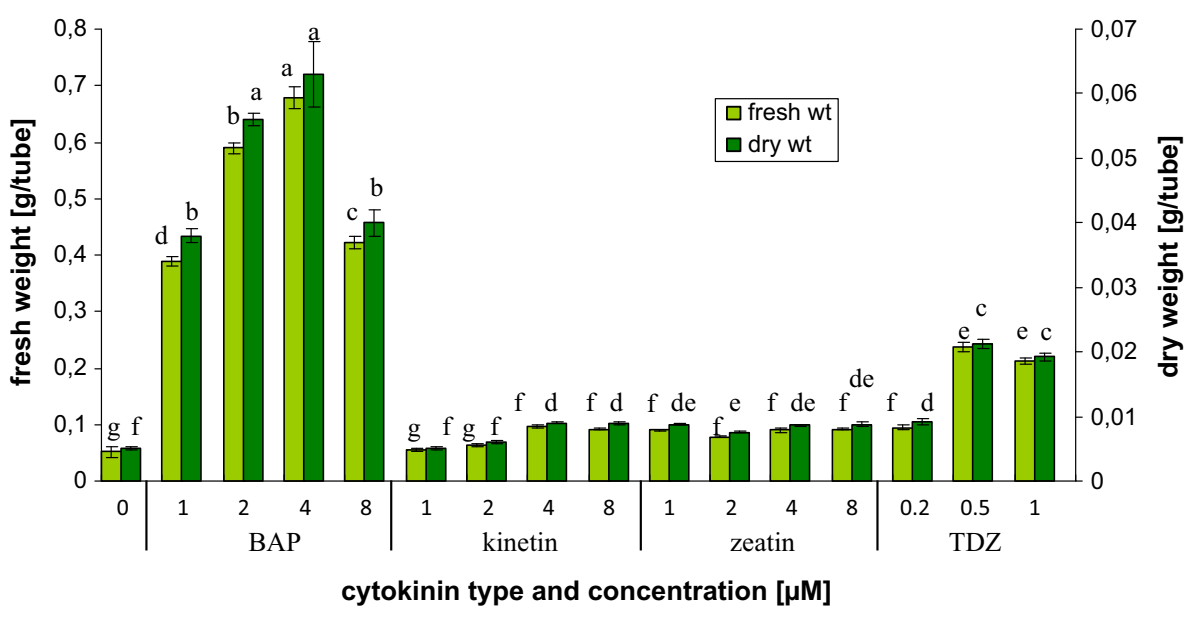

Fig. 2 The effect of various cytokinins and their concentrations on fresh weight and dry weight of S. alpina shoots after 5 weeks of culture on MS medium with IAA $(0.57 \mu \mathrm{M})$. The results are expressed as means of three replicates $\pm \mathrm{SE}$. The means with the same letter for the same parameter do not differ significantly according to the Kruskal-Wallis test $(p \leq 0.05)$

cytokinin type and concentration [ $\mu \mathrm{M}]$
$4 \mu \mathrm{M}$ (23.5 per explant). However, increasing the BAP concentration to $8 \mu \mathrm{M}$ or decreasing it to $1 \mu \mathrm{M}$ resulted in a significant reduction in the number of shoots to 17.2 and 18.5 per explant, respectively. Most of the shoots grown in the presence of BAP demonstrated normal morphology and had well developed leaves; a maximum $9 \%$ of proliferating shoots were hyperhydrated with a reduced number of leaves when the highest BAP concentration $(8 \mu \mathrm{M})$ was used. In the presence of other cytokinins, the multiplication rate of $S$. alpina shoots was significantly lower and ranged from 6.4 to 8.2 for TDZ, from 3.0 to 6.8 for kinetin and from 5.3 to 6.9 for zeatin (Fig. 1). The quantitative response of the different cytokinins on shoot length is presented in Fig. 1. Shoot length was the greatest on the control medium $(8.05 \mathrm{~cm})$, followed by $1-4 \mu \mathrm{M}$ zeatin supplementation $(5.4-5.5 \mathrm{~cm})$. The shortest shoots $(1.8-1.9 \mathrm{~cm})$ were obtained on medium supplemented with higher concentrations of BAP $(4-8 \mu \mathrm{M})$.

The addition of cytokinin to the auxin-containing medium $(0.57 \mu \mathrm{M}$ IAA) also significantly increased the mean dry and fresh weights of cultures, except in the presence of 1 and $2 \mu \mathrm{M}$ kinetin (Fig. 2). In these cases, no significant differences were observed in the number of shoots produced per explant when compared to those on the control medium (Fig. 1). The highest biomass (dry and fresh weight per culture vessel) was achieved for $S$. alpina shoots cultured in the presence of $4 \mu \mathrm{M}$ BAP: a 78 -fold increase in fresh weight $(0.678 \mathrm{~g}$ per tube from an initial inoculum of $0.0087 \mathrm{~g}$ per tube) and a 74-fold increase in dry weight $(0.063 \mathrm{~g}$ per tube from an initial inoculum of $0.00085 \mathrm{~g}$ per tube) were observed after 5 weeks of culture on the medium. Similar results were obtained in the shoot culture treated with $2 \mu \mathrm{M}$ BAP (Fig. 2).

\section{Effect of cytokinins on polyphenolic compound production}

Verbascoside, baicalin, wogonoside, luteolin and luteolin 7-O-glucoside were identified in all S. alpina shoot extracts 
by a comparison of their retention times, UV spectra and mass spectra with those of standard compounds (Grzegorczyk-Karolak et al. 2013). However, the level of the polyphenolic compounds was quantitatively modified by the type and concentration of cytokinin present in the culture medium (MS with $0.57 \mu \mathrm{M}$ IAA) (Fig. 3).

The predominant metabolite was baicalin. Its content in S. alpina shoot biomass ranged from 4.53 to $18.79 \mathrm{mg} \mathrm{g}^{-1}$ dry weight (wt) (Fig. 3b). The maximum amount of the metabolite was found in the extract from the biomass of shoots growing on the medium containing $0.5 \mu \mathrm{M}$ TDZ. Baicalin content fell to around $75 \%$ of the amount when lower $(0.2 \mu \mathrm{M})$ and higher $(1 \mu \mathrm{M})$ concentrations of TDZ were used (Fig. 3b). The levels of baicalin in shoots grown on the media containing TDZ were 3-4 times higher than those seen in the control medium, i.e. MS supplemented only with auxin. Also, the addition of other cytokinins (BAP, kinetin, zeatin) to a medium supplemented with $0.57 \mu \mathrm{M}$ IAA stimulated the accumulation of baicalin in proliferating shoots, especially when they were added at higher concentrations (4 or $8 \mu \mathrm{M})$. For example, baicalin production by shoots grown on media containing $0.57 \mu \mathrm{M}$ IAA and $8 \mu \mathrm{M}$ BAP or zeatin was approximately $12.5 \mathrm{mg} \mathrm{g}^{-1}$ dry wt, while that of shoots grown at an equimolar concentration of kinetin was $15.5 \mathrm{mg} \mathrm{g}^{-1}$ dry wt (Fig. 3b). The levels were about $20-30 \%$ less than in the shoots grown in the presence of $0.5 \mu \mathrm{M}$ TDZ.

A similar tendency was noted with respect to wogonoside, although the flavone was found in S. alpina shoot cultures in lower amounts than baicalin. The greatest wogonoside content $\left(7.04 \mathrm{mg} \mathrm{g}^{-1}\right.$ dry wt) was observed in the presence of $0.5 \mu \mathrm{M}$ TDZ, this value being about 1.5 times more than on media containing 0.2 or $1.0 \mu \mathrm{M}$ of the cytokinin and up to 9 times more compared to the control medium ( $0.78 \mathrm{mg} \mathrm{g}^{-1}$ dry wt) (Fig. 3c). High levels of wogonoside (above $4 \mathrm{mg} \mathrm{g}^{-1}$ dry wt) were also found in the shoots grown on media supplemented with $8 \mu \mathrm{M}$ BAP, $8 \mu \mathrm{M}$ zeatin or $4 \mu \mathrm{M}$ kinetin (Fig. 3c).

TDZ was also more effective than the other cytokinins tested (BAP, zaeatin, kinetin) for verbascoside production. Its quantity was highest in the shoots multiplied on media containing 0.5 or $1 \mu \mathrm{M}$ TDZ combined with $0.57 \mu \mathrm{M}$ IAA $\left(9.76 \mathrm{mg} \mathrm{g}^{-1}\right.$ dry wt and $9.36 \mathrm{mg} \mathrm{g}^{-1}$ dry wt, respectively). The levels were about $40 \%$ higher than that found on the control medium (MS without cytokinin). However, supplementation with zeatin $(2$ and $4 \mu \mathrm{M})$, kinetin $(1 \mu \mathrm{M})$ and BAP $(1$ and $8 \mu \mathrm{M})$ resulted in lower verbascoside production compared to treatment with auxin only $(0.57 \mu \mathrm{M}$ IAA). The lowest content of the phenylethanoid (3.75 $\mathrm{mg} \mathrm{g}^{-1}$ dry wt) was reached on MS medium supplemented with $1 \mu \mathrm{M}$ kinetin (Fig. 3a).
The quantity of luteolin was reduced below that observed in the control shoots following treatment with cytokinin (Fig. 3d). Only cultures treated with $2 \mu \mathrm{M}$ BAP displayed amounts of luteolin similar to those of the control (about $3.5 \mathrm{mg} \mathrm{g}^{-1}$ dry wt). These cultures also revealed significantly higher luteolin 7-glucoside levels than controls (1.68 vs $1.39 \mathrm{mg} \mathrm{g}^{-1}$ dry wt). In the other hormonal variants, the luteolin 7-glucoside levels were either lower or identical to those recorded in the control (Fig. 3d). It should also be noted that although the different types and concentrations of cytokinins have varying degrees of influence on the production of luteolin and its glucoside, the ratios between these compounds tend to be similar in the $S$. alpina shoots, ranging from approximately 1.9 to 2.3:1. Exceptionally, treatment with $1 \mu \mathrm{M} \mathrm{TDZ}$ resulted in a luteolin content only $50 \%$ more than that of its glucoside (Fig. 3d).

\section{Antioxidant activity}

The ABTS and FRAP in vitro assays were used to evaluate the antioxidant activity of methanolic extracts from $S$. alpina shoot cultures multiplied on MS medium supplemented with BAP, kinetin, zeatin or TDZ. Extract of shoots from MS medium containing $0.57 \mu \mathrm{M}$ IAA, without cytokinin, was used as control. The ABTS test was used to characterize antiradical scavenging properties, while the FRAP assay was employed to measure the capacity of the extracts to reduce ferric ions $\left(\mathrm{Fe}^{3+}\right.$ to $\left.\mathrm{Fe}^{2+}\right)$. The results are presented in Fig. 4.

Similarly to secondary metabolites, an exogenous supply of a cytokinin was found to significantly affect the antioxidant properties of analyzed shoot cultures (Fig. 4). The ABTS assay revealed the free radical scavenging activity of shoot cultures, expressed as $\mathrm{EC}_{50}$, to range from 28.27 to $118.56 \mu \mathrm{g} \mathrm{ml}^{-1}$, while the FRAP test of the same extracts found reducing power to range from 775.62 $\mathrm{Fe}(\mathrm{II}) \mathrm{g}^{-1}$ extract dry wt to $265.73 \mathrm{Fe}$ (II) $\mathrm{g}^{-1}$ extract dry wt. For both assays, the highest activity was found in shoots grown with $0.5 \mu \mathrm{M} \mathrm{TDZ}$, which was also characterized by the highest level of secondary metabolites analyzed. The $\mathrm{EC}_{50}$ values indicated that the weakest free radical scavenging properties were found for plant material cultured on medium supplemented only with auxin (control), and shoots kept in the presence of auxin combined with 2 and $4 \mu \mathrm{M}$ zeatin (Fig. 4). The extracts which exhibited the weakest effects on reducing ferric ions were those from shoots grown on medium supplemented with $2 \mu \mathrm{M}$ zeatin and those treated with $1 \mu \mathrm{M}$ kinetin.

The analysis of correlation coefficient values revealed a strong relationship between the antioxidant activity of shoot cultures treated with different cytokinins and the 

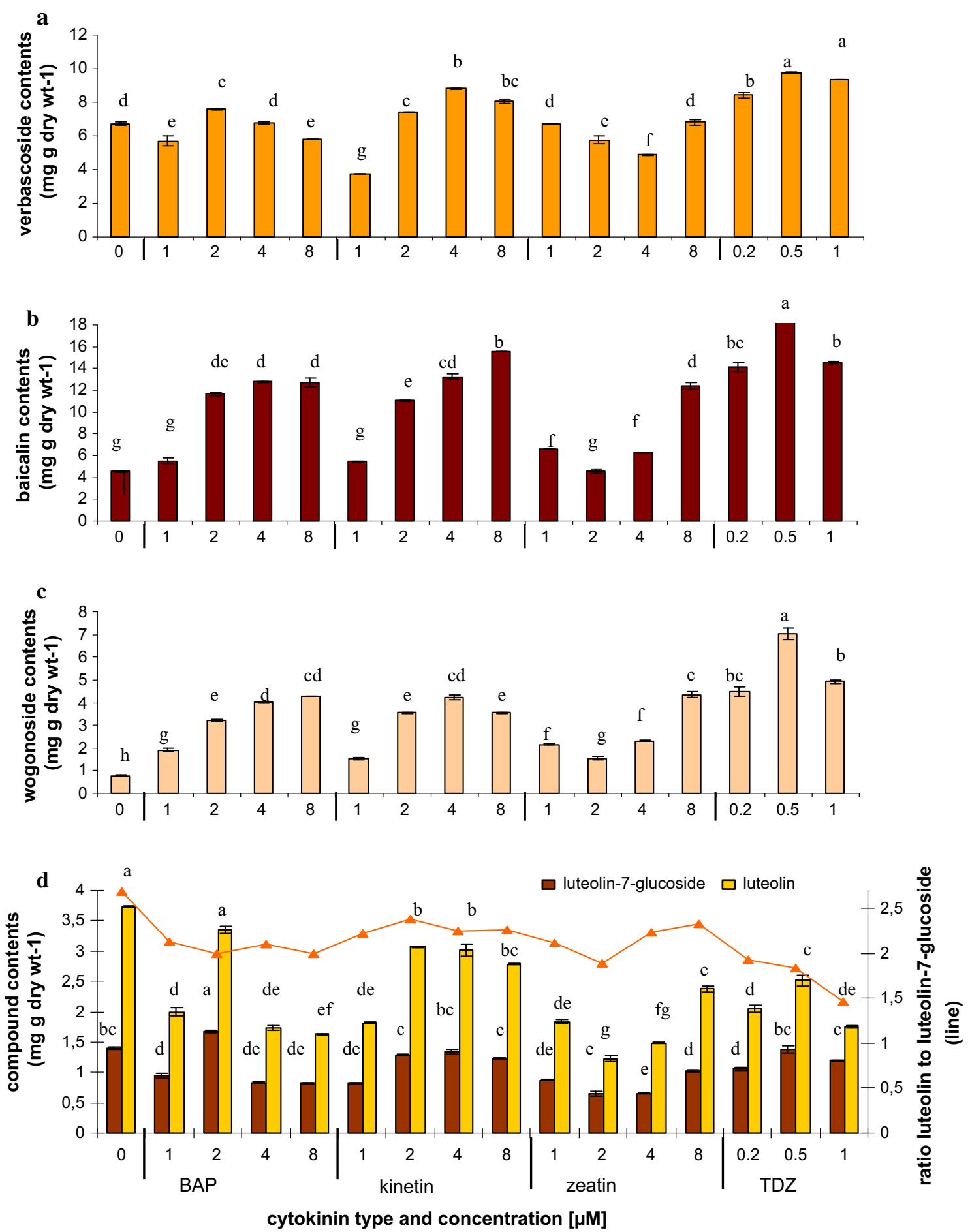

Fig. 3 The effect of various cytokinins and their concentrations on polyphenolic compound a verbascoside, b baicalin, c wogonoside, d luteolin and luteolin-7-glucoside) production in S. alpina shoots after 5 weeks of culture on MS medium with IAA $(0.57 \mu \mathrm{M})$. The

total polyphenolic compound content, calculated as the sum of verbascoside, baicalin, wogonoside, luteolin, luteolin 7-glucoside, $(r=0.97$ and -0.93 for FRAP and results are expressed as means of three replicates \pm SE. The means with the same letter for the same parameter do not differ significantly according to the Kruskal-Wallis test $(p \leq 0.05)$

ABTS assays, respectively). Some correlations were also found with the content of some individual compounds (Table 1). 


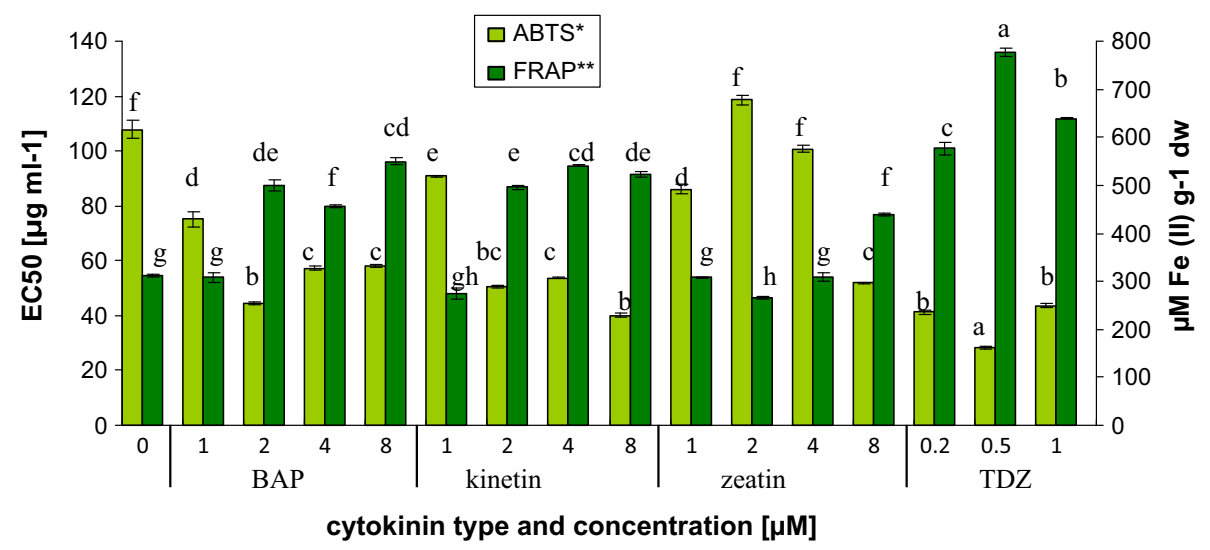

Fig. 4 Antioxidant activities of S. alpina shoot extracts determined by the ABTS radical scavenging and reducing power (FRAP) assays. The results are expressed as mean $\pm \mathrm{SE}$. The means with the same letter for the same test do not differ significantly according to the
Kruskal-Wallis test $(p \leq 0.05)$. Single asterisk $\mathrm{EC}_{50}$ the concentration of sample $\left(\mu \mathrm{g} \mathrm{ml}^{-1}\right)$ showing $50 \%$ of maximal radical scavenging activity. Double asterisk Ferric reducing antioxidant power expressed in $\mu \mathrm{M} \mathrm{Fe}(\mathrm{II}) \mathrm{g}^{-1} \mathrm{dw}$
Table 1 Comparison of correlation coefficient (r) between different parameters (biomass, proliferation rate, antioxidant assays) and metabolite (verbascoside, baicalin, wogonoside, luteolin-7-glucoside, luteolin, total polyphenolic) contents in S. alpina shoot cultures grown on MS media with IAA $(0.57 \mu \mathrm{M})$ and different type and concentrations of cytokinins

\begin{tabular}{|c|c|c|c|c|c|}
\hline & $\begin{array}{l}\text { Shoot } \\
\text { proliferation }\end{array}$ & $\begin{array}{l}\text { Fresh wt } \\
\left(\mathrm{g} \mathrm{tube}^{-1}\right)\end{array}$ & $\begin{array}{l}\text { Dry wt } \\
\left(\mathrm{g}_{\text {tube }}{ }^{-1}\right)\end{array}$ & $\begin{array}{l}\text { ABTS } \\
\mathrm{EC}_{50}\left(\mu \mathrm{g} \mathrm{ml}^{-1}\right)\end{array}$ & $\begin{array}{l}\text { FRAP }(\mu \mathrm{M} \text { Fe(II) } \\
\mathrm{g}^{-1} \text { dry wt) }\end{array}$ \\
\hline Verbascoside & -0.02 & 0.04 & 0.02 & -0.74 & 0.84 \\
\hline Baicalin & 0.17 & 0.23 & 0.22 & -0.93 & 0.95 \\
\hline Wogonoside & 0.15 & 0.23 & 0.21 & -0.86 & 0.94 \\
\hline Luteolin-7-glucoside & 0.10 & 0.10 & 0.10 & -0.56 & 0.54 \\
\hline Luteolin & -0.04 & -0.07 & -0.06 & -0.29 & 0.22 \\
\hline Total polyphenols ${ }^{\mathrm{a}}$ & 0.13 & 0.19 & 0.17 & -0.93 & 0.97 \\
\hline
\end{tabular}

Bold values indicate strong or very strong correlation

${ }^{a}$ Total polyphenolic compound content calculated as the sum of verbascoside, baicalin, wogonoside, luteolin and luteolin 7-glucoside

\section{Discussion}

The current study is the first to evaluate the role of different types of cytokinin, i.e. BAP, kinetin, zeatin and TDZ, in combination with $0.57 \mu \mathrm{M}$ IAA on S. alpina shoot culture: its growth, shoot proliferation, secondary metabolite production and antioxidant activity. Almost all cytokinins increased shoot multiplication, apart from kinetin at concentrations of 1 and $2 \mu \mathrm{M}$. Among these, 2 and $4 \mu \mathrm{M}$ BAP were the most effective treatments, producing 23-25 shoots per explant within 5 weeks of culture. BAP has been reported to be more efficient at inducing shoot proliferation than other cytokinins in many other plants, including some Scutellaria species. Joshee et al. (2007) found the maximum number of shoots from shoot tips of $S$. integrifolia $(23$ per explant) to be obtained on MS medium supplemented with $2.2 \mu \mathrm{M}$ BAP, while for $S$. discolor the best results were obtained in the presence of $4.4 \mu \mathrm{M}$ BAP (Sinha et al. 1999). Also, the increase in fresh and dry biomass of $S$. alpina shoots grown for 5 weeks on media containing BAP was largest, although the shoots were shorter than those grown in the presence of other tested cytokinins, especially kinetin and zeatin, and those cultured on control medium (MS without cytokinin). These findings suggest that shoot biomass could be affected more by proliferation rate than the growth of individual shoots.

The results of the present study confirm that changes in the type and concentration of cytokinin applied can drastically affect product accumulation. For example, cytokinins have been reported to increase production of alkaloids in cell cultures of Catharanthus roseus (Decendit et al. 1992), lignans in Phyllanthus amarus shoots (Nitnaware et al. 2011) and anthocyanins in Oxalis linearis callus (Meyer and van Staden 1995). Conversely, they have also been observed to inhibit secoiridoid production in Blackstonia perfoliata shoots (Sabovljevic et al. 2006) and rutin in the callus and adventitious root culture of Morus alba (Lee et al. 2011). The findings of the present study 
demonstrate that total polyphenolic content (calculated as the sum of verbascoside, baicalin, wogonoside, luteolin and luteolin 7-glucoside) in S. alpina shoot cultures varied from 13.37 to $39.49 \mathrm{mg} \mathrm{g}^{-1}$ dry wt, which was found to be much higher under optimal cytokinin conditions than in cytokinin-free controls $\left(17.15 \mathrm{mg} \mathrm{g}^{-1}\right.$ dry wt). This difference is a result of the positive effect of suitable concentrations of cytokinins on the accumulation of baicalin, wogonoside and verbascoside. A different tendency was observed regarding luteolin and luteolin 7-O-glucoside: luteolin concentration was significantly lower in $S$. alpina shoots grown in the presence of cytokinins, except $2 \mu \mathrm{M}$ BAP, than those grown on control medium.

Although BAP was more effective in improving $S$. alpina shoot proliferation and biomass production than TDZ, TDZ was more effective than BAP, kinetin and zeatin in inducing baicalin, wogonoside and verbascoside production. These findings indicate that polyphenolic compound production in S. alpina shoot culture is not associated with biomass accumulation, as confirmed by a correlation coefficient (r) lower than 0.23 between the concentrations of analyzed compounds and the fresh and dry weights of $S$. alpina shoot cultures treated with the cytokinins (Table 1). Biomass-independent production of total phenolic content was also recently reported by Ali et al. (2013) in callus cultures of Artemisia absinthium.

The highest amounts of baicalin, wogonoside and verbascoside were observed in the $S$. alpina shoots grown in the presence of $0.5 \mu \mathrm{M}$ TDZ. Under these conditions, baicalin content (18.8 $\mathrm{mg} \mathrm{g}^{-1}$ dry wt) was 8.5 times higher than that observed in the aerial parts of field-grown plants of S. alpina (Zgórka 2006). The present study represents the first description of the wogonoside content of S. alpina. Comparing these findings and those of Islam et al. (2011) with other closely related and pharmacological important Scutellaria species, the following observations can be made. The accumulation of wogonoside in S. alpina shoots grown on MS medium supplemented with $0.5 \mu \mathrm{M} \mathrm{TDZ}$ can be seen to be greater than that found in the leaves, stems and roots of S. racemosa $\left(0-2.05 \mathrm{mg} \mathrm{g}^{-1}\right.$ dry wt) and $S$. tomentosa $\left(0-5.68 \mathrm{mg} \mathrm{g}^{-1}\right.$ dry wt), as well as the stems of $S$. baicalensis (5.6 $\mathrm{mg} \mathrm{g}^{-1}$ dry wt). However, these levels are lower than those observed in the roots of $S$. baicalensis, which were found to contain $12 \mathrm{mg} \mathrm{g}^{-1}$ dry wt of wogonoside. Although the roots of $S$. baicalensis also contained the highest level of verbascoside of the Scutellaria plants, (2.35 $\mathrm{mg} \mathrm{g}^{-1}$ dry wt) (Islam et al. 2011), this value was significantly lower than that previously observed by Nishikawa et al. (1999) in the roots of S. alpina, which produced about $2.8 \%$ dry weight of verbascoside. This level was three times higher than that obtained in our shoot culture of S. alpina grown under optimized cytokinin conditions: i.e. on MS medium in the presence of TDZ $(0.5$ or $1 \mu \mathrm{M})$ (about $9.5 \mathrm{mg} \mathrm{g}^{-1}$ dry wt).

The stimulatory effect of TDZ on axillary shoot proliferation and adventitious shoot induction is well documented. However, the effect of TDZ on the biosynthesis of secondary metabolites has rarely been investigated and it is not clear how TDZ increases the production of flavones (baicalin and wogonoside) or phenylethanoid glycoside (verbascoside) in S. alpina shoot culture. According to Ramawet and Merrilion (1999), the plant growth regulators do not react with the intermediate compounds of the biosynthetic pathway, but appear to change cytoplasmatic conditions for product formation. Sakakibara (2006) speculate that cytokinin significantly suppresses the transport of macronutrients such as nitrate, ammonium, sulfate and phosphate, while nitrate regulates the expression of genes involved in the phenylpropanoid and flavonoid pathways. Previous studies report that while TDZ is believed to be the cytokinin responsible for elevated production of hypericin in Hypericum perforatum shoot culture (Liu et al. 2007), it is also responsible for reducing the levels of hypericin and pseudohypericin in $H$. maculatum and H. sampsonii shoots (Coste et al. 2011; Liu et al. 2007). In our study, TDZ decreased luteolin and luteolin 7-glucoside levels in shoot culture of S. alpina in a similar way to other cytokinins, such as kinetin, zeatin and BAP (with the exception of $2 \mu \mathrm{M}$ BAP). The similarity between the biochemical pathways of luteolin and its glucoside in shoot cultures treated with cytokinins was confirmed by the high positive correlation between their ratio obtained (0.88). The high positive correlations between baicalin, wogonoside and to an extent, verbascoside biosynthesis, and the weak correlation between these polyphenols and the biosynthesis of luteolin and its glucoside suggest that accumulation of these phytochemicals in the presence of cytokinins can occur via different pathways.

The present study is the first to evaluate the antioxidant potential of S. alpina. The antioxidant activity of S. alpina, as assessed by the ABTS and FRAP tests, was found to have a strong correlation with total polyphenolic levels in shoot extracts. Such a relationship is not surprising and has been previously published for many other phenolic-rich species of the Lamiaceae family such as Salvia officinalis (Grzegorczyk-Karolak et al. 2007), Lycopus lucidus (Ślusarczyk et al. 2009) or Dracocephalum moldavica (Weremczuk-Jeżyna et al. 2013).

\section{Conclusion}

The present study demonstrates that $S$. alpina can be successfully propagated in vitro using shoot tip explants. Of the cytokinins tested, BAP was the most effective for shoot 
proliferation and biomass production. The type of cytokinin and its concentration was also found to significantly influence the accumulation of bioactive metabolites $S$. alpina shoot cultures and their antioxidant activity. These findings indicate that shoots regenerated from shoot tips on MS medium containing auxin $(0.57 \mu \mathrm{M}$ IAA) and $0.5 \mu \mathrm{M}$ TDZ can be a rich source of baicalin, wogonoside and verbascoside, compounds with many therapeutic properties. Further research is needed to evaluate whether production of the metabolites in S. alpina shoots depends on the type and concentration of auxin combined with TDZ, and how this can be the case.

Open Access This article is distributed under the terms of the Creative Commons Attribution 4.0 International License (http://creativecommons.org/licenses/by/4.0/), which permits unrestricted use, distribution, and reproduction in any medium, provided you give appropriate credit to the original author(s) and the source, provide a link to the Creative Commons license, and indicate if changes were made.

\section{References}

Ali M, Abbasi BH, ul-haq I (2013) Production of commercially important secondary metabolites and antioxidant activity in cell suspension cultures of Artemisia absinthium L. Ind Crops Prod 49:400-406. doi:10.1016/j.indcrop.2013.05.033

Chang WH, Chem CH, Lu FJ (2002) Different effects of baicalein, baicalin and wogonin on mitochondrial function, glutathione content and cell cycle progression in human hepatoma cell lines. Planta Med 68:128-132. doi:10.1055/s-2002-20246

Chen Y, Lu N, Ling Y, Gao Y, Wang L, Sun Y, Qi Q, Feng F, Liu W, You Q, Gao Q (2009) Wogonoside inhibits lipopolysaccharideinduced angiogenesis in vitro and in vivo via toll-like receptor 4 signal transduction. Toxicology 259:10-17. doi:10.1016/j.tox. 2009.01.010

Cheng Y, He G, Mu X, Zhang T, Li X, Hu J, Xu B, Du G (2008) Neuroprotective effect of baicalein against MPTP neurotoxicity: behavioral, biochemical and immunohistochemical profile. Neurosci Lett 441:16-20. doi:10.1016/j.neulet.2008.05.116

Cole IB, Praveen KS, Murch SJ (2007) Medicinal biotechnology in the genus Scutellaria. In Vitro Cell Dev Biol Plant 43:318-327. doi:10.1007/s11627-007-9055-4

Cole IB, Cao J, Alan AR, Saxena PK, Murch SJ (2008) Comparisons of Scutellaria baicalensis, Scutellaria lateriflora and Scutellaria racemosa: genome size, antioxidant potential and phytochemistry. Planta Med 74:474-481. doi:10.1055/s-2008-1034358

Coste A, Vlase L, Halmagyi A, Deliu C, Coldea G (2011) Effects of plant growth regulators and elicitors on production of secondary metabolites in shoot cultures of Hypericum hirsutum and Hypericum maculatum. Plant Cell Tiss Organ Cult 106:279_ 288. doi:10.1007/s11240-011-9919-5

Decendit A, Liu D, Ouelhazi L, Doireau P, Mérillon JM, Rideau M (1992) Cytokinin-enhanced accumulation of indole alkaloids in Catharanthus roseus cell cultures - the factors affecting the cytokinin response. Plant Cell Rep 11:400-403. doi:10.1007/BF00234369

Gao Z, Huang K, Yang X, Xu H (1999) Free radical scavenging and antioxidant activities of flavonoids extracted from the radix of Scutellaria baicalensis Georgi. Biochim Biophys Acta 1472:643-650. doi:10.1016/S0304-4165(99)00152-X
Grzegorczyk I, Matkowski A, Wysokińska H (2007) Antioxidant activity of extracts from in vitro cultures of Salvia officinalis L. Food Chem 104:536-541. doi:10.1016/j.foodchem.2006.12.003

Grzegorczyk-Karolak I, Kuźma Ł, Wysokińska H (2013) The use of long-term Scutellaria altissima callus cultures for shoot regeneration, production of bioactive metabolites and micropropagation. J Med Plants Res 7:3003-3313. doi:10.5897/JMPR2013. 5226

Grzegorczyk-Karolak I, Kuźma Ł, Wysokińska H (2015) Study on the chemical composition and antioxidant activity of extracts from shoot culture and regenerated plants of Scutellaria altissima L. Acta Physiol Plant 37:1736-1744. doi:10.1007/s11738-0141736-0

Guo B, Abbasi BH, Zeb A, Xu LL, Wei YH (2011) Thidiazuron: a multi-dimensional plant growth regulator. Afr J Biotechnol 10:8984-9000. doi:10.5897/AJB2013.12456

He XL, Wang YH, Gao M, Li XX, Zhang TT, Du GH (2009) Baicalein protects rat brain mitochondria against chronic cerebral hypoperfusion-induced oxidative damage. Brain Res 1249: 212-221. doi:10.1016/j.brainres.2008.10.005

Islam MN, Downey F, Ng CY (2011) Comparative analysis of bioactive phytochemicals from Scutellaria baicalensis, Scutellaria lateriflora, Scutellaria racemosa, Scutellaria tomentosa and Scutellaria wrightii by LC-DAD-MS. Metabolomics 7:446-453. doi:10.1007/s11306-010-0269-9

Joshee N, Mentreddy SR, Yadav AK (2007) Mycorrhizal fungi and growth and development of micropropagated Scutellaria integrifolia plants. Ind Crops Prod 25:169-177. doi:10.1016/j. indcrop.2006.08.009

Kernan MR, Amarquaye A, Chen J, Chan LDFJ, Sesin N, Parkinson ZJ, Barrett C, Ye M, Stoddart CA, Sloan B, Blanc P, Limbach C, Mrisho S, Rozhon EJ (1998) Antiviral phenylpropanoid glycosides from the medicinal plant Markhamia lutea. J Nat Prod 61:564-570. doi:10.1021/np9703914

Kitamura K, Honda M, Yoshizaki H, Yamamoto S, Nakane H, Fukushima M, Ono K, Tokunaga T (1998) Baicalin, an inhibitor of HIV-1 production in vitro. Antiviral Res 37:131-140. doi:10. 1016/S0166-3542(97)00069-7

Lee Y, Lee DE, Lee HS, Kim KS, Lee WS, Kim SH, Kim MW (2011) Influence of auxins, cytokinins, and nitrogen on production of rutin from callus and adventitious roots of the white mulberry tree (Morus alba L.). Plant Cell Tiss Organ Cult 105:9-19. doi:10.1007/s11240-010-9832-3

Lim BO (2003) Effects of wogonin, wogonoside, and 3,5,7,2', $6^{\prime}$ pentahydroxyflavone on chemical mediator production in peritoneal exduate cells and immunoglobulin $\mathrm{E}$ of rat mesenteric lymph node lymphocytes. J Ethnopharmacol 84:23-29. doi:10. 1016/S0378-8741(02)00257-X

Liu XN, Zhang XQ, Sun JS (2007) Effects of cytokinins and elicitors on the production of hypericins and hyperforin metabolites in Hypericum sampsonii and Hypericum perforatum. Plant Growth Regul 53:207-214. doi:10.1007/s10725-007-9220-0

Meyer HJ, van Staden J (1995) The in vitro production of an anthocyanin from callus cultures of Oxalis linearis. Plant Cell Tiss Organ Cult 40:55-58. doi:10.1007/BF00041119

Murashige T, Skoog F (1962) A revised medium for rapid growth and bioassays with tobacco tissue cultures. Physiol Plant 15:473-497. doi:10.1111/j.1399-3054.1962.tb08052.x

Nishikawa K, Ishimaru K (1997) Flavonoids in root cultures of Scutellaria baicalensis. J Plant Physiol 151:633-636

Nishikawa K, Furukawa H, Fujioka T, Fujii H, Mihashi K, Shimomura K, Ishimaru K (1999) Phenolics in tissue cultures of Scutellaria. Nat Med 53:209-213

Nitnaware KM, Naik DG, Nikam TD (2011) Thidiazuron-induced shoot organogenesis and production of hepatoprotective lignan phyllanthin and hypophyllanthin in Phyllanthus amarus. Plant 
Cell Tiss Organ Cult 104:101-110. doi:10.1007/s11240-0109796-3

Pettit RG, Numata A, Takemura T, Ode RH, Nurula AS, Schmidt JM, Cragg GM, Pase CP (1990) Isolation of acteoside and isoacteoside from Castilleja linariaefolia. J Nat Prod 53:456-458. doi:10.1021/np50068a026

Pulido R, Bravo L, Saura-Calixto F (2000) Antioxidant activities of dietary phenols are determined by a modified ferric reducing/ antioxidant power assay. J Agric Food Chem 48:3396-3402. doi:10.1021/jf9913458

Ramawet K, Merrilion J (1999) Biotechnology - secondary metabolites. Mohan Primlani for Oxford and YBH, Delhi, pp 243-247

Re R, Pellegrini N, Proteggente A, Pannala A, Yang M, Rice-Evans C (1999) Antioxidant activity applying an improved ABTS radical cation decolorizing assay. Free Radical Biol Med 26:1231-1237. doi:10.1016/S0891-5849(98)00315-3

Sabovljevic A, Rosic N, Jankovic T, Grubisic D (2006) Secoiridoid content of Blackstonia perfoliata in vivo and in vitro. In Vitro Cell Dev Biol. Plant 42:427-431. doi:10.1079/IVP2006759

Sakakibara H (2006) Cytokinins: activity, biosynthesis and translocation. Annu Rev Plant Biol 57:431-449

Seo WT, Park YH, Choe TB (1993) Identification and production of flavonoids in a cell-suspension culture of Scutellaria baicalensis Georgi. Plant Cell Rep 12:414-417. doi:10.1007/BF00234703

Shang XF, He XR, He XY, Li MX, Zhang RX, Fan PC, Zhang QL, Jia ZP (2010) The genus Scutellaria an ethnopharmacological and phytochemical review. J Ethnopharmacol 128:279-313. doi:10.1016/j.jep.2010.01.006

Shoyama Y, Matsumoto M, Nishioka I (1986) Four caffeoyl glycosides from callus tissue of Rehmannia glutinosa. Phytochem 25:1633-1636. doi:10.1016/S0031-9422(00)81224-8
Sinha S, Pokhrel S, Vaidya BN, Joshee N (1999) In vitro micropropagation and callus induction in Scutellaria discolor Colebr.- A medicinally important plant of Nepal. Indian J Pl Genet Resources 12:219-223

Ślusarczyk S, Hajnos M, Skalicka-Woźniak K, Matkowski A (2009) Antioxidant activity of polyphenols from Lycopus lucidus Turcz. Food Chem 113:134-138. doi:10.1016/j.foodchem.2008.07.037

Stojakowska A, Kisiel W (1998) Secondary metabolites from a callus culture of Scutellaria colomnae. Fitoterapia 70:324-325. doi:10. 1016/S0367-326X(99)00022-2

Takasuna K, Kasai Y, Kitano Y, Mori K, Kobayashi R, Hagiwara T, Kakihata K, Hirohashi M, Nomura M, Nagai E et al (1995) Protective effects of kampo medicines and baicalin against intestinal toxicity of a new anticancer camptothecin derivative, irinotecan hydrochloride (CPT-11), in rats. Jpn J Cancer Res 86:978-984

Weremczuk-Jeżyna I, Grzegorczyk-Karolak I, Frydrych B, Królicka A, Wysokińska H (2013) Hairy roots of Dracocephalum moldavica: rosmarinic acid content and antioxidant potential. Acta Physiol Plant 35:2095-2103. doi:10.1007/s11738-0131244-7

Woo KJ, Lim JH, Suh SI, Kwon YK, Shin SW, Kim SC, Choi YH, Park JW, Kwon TK (2006) Differential inhibitory effects of baicalein and baicalin on LPS-induced cyclooxygenase-2 expression through inhibition of C/EBP $\beta$ DNA-binding activity. Immunobiology 211:359-368. doi:10.1016/j.imbio.2006.02.002

Zgórka G (2006) Retention behavior of silica bonded and novel polymeric reversed phase sorben ts in studies on flavones as chemotaxonomic markers of Scutellaria L. genus. J Chromatogr A 1120:230-236 